\title{
STRATEGI PENGEMBANGAN AGRIBISNIS \\ MELALUI AGRIBUSINESS DEVELOPMENT CENTER \\ DALAM MEMBANGUN KEMITRAAN AGRIBISNIS \\ (STUDI PADA PENGEMBANGAN SENTRA USAHA PETERNAKAN SAPI KECAMATAN TAWANGSARI, KABUPATEN SUKOHARJO)
}

\author{
Sugiharti Mulya H, R. Kunto Adi, , Setyowati, Susi Wuri Ani \\ Fakultas Pertanian UNS, Jl. Ir. Sutami, No : 36A Ska, 0271637457
}

Abstract. Development Strategy Of Agribusiness With Agribusiness Development Center In Developing Agribusiness Partnership (Study In Development Of Cattle Cow Central At Tawangsari Sub District, Sukoharjo Regency). This research aimed to identify needs and problems the small and medium enterprises of agribusiness, to formulate the internal and external factors in to strenghtness, weakness, opportunities and treatness in development of agribusiness, to formulate alternative strategies in development of agribusiness with agribusiness development center ini developing of agribusiness partnership, to formulate the priority strategies in development of agribusiness with agribusiness development center ini developing of agribusiness partnership, and to formulate the value chain in development of agribusiness with agribusiness development center in developing of agribusiness partnership at Sukoharjo Regency. The basic method used in this research is descriptive analytic method with survey techniques and focus group discussion. The method to determine the location of the research done by purposive, namely Sukohario Regency. Sampling method to determine the factors internal and external done snowball, while the method of determining the weight and Attractiveness Score (AS) performed intentionally (purposively). Data type applied in this research is primary data and secondary data. Data analysis method applied were SWOT analysis, SWOT matrix, QSP matrix, and value chain analysis. The results of SWOT analysis to show internal factors that the strengths in developing agribusiness of cattle cow were a large of many and expand of cattle breeder di Sukoharjo Regency, quality of cow were good and continuity of production, a large of many in potency of nature resources, institution of cluster were strength. The weakness were production factors are limited, especially of cattle food, a low of capacity of human resources in to access for breeding and technology, health of cow, access of market and information of price, a lack of marketing, a low of optimally in management of cattle, management of cattle still traditionally, and hereditary, and so a lack of capital capacity. The external factors that the opportunities were simplify of capital access at banking, institution of micro finance, credits with light of interest, a large of foods cattle from small and medium enterprises central else, a demand of meat cow and product of meat cow processing, a development policy of small and medium enterprises from province and state government, technology processing of process remainder of cattle, easier of development quality of meat and breeding. The treathness were a limited of superior of seed, a limited of production factors, especially of food cattle, a association or cooperation of cattle breeder was not yet, a import policy of meat cow, a policy programme of small and medium enterprises development was not well coordinated, a finance capacity of regional government for development of small and medium enterprises was limited, a technology processing of remainder process of cattle was limited, a infection of antrax disease from other location and other disease that lack of prediction, a price competition of cow with other location from Sukoharjo Regency that usually of lower price. The results of SWOT Matrix 
and QSP to show priority strategies can be applied in development agribusiness of cattle cow were developing and to defend of quality and continuity production to endure in the markets, with development of production capacity and technology, and so cluster institution with supported by coordinativelly stakeholders, so that strengthening of bargaining position of cattle breeder, to develop capacity of human resources of cattle breeder for developing access in to production factors and technology, to develop business management, to defend and expanding markets access, with coordination and cooperation with stakeholders as like non regional government institution, and to defend of production quality and continuity by partnership with other central of small and medium enterprises in performing of production factors and distribution networking.

\section{Key Words: Strategy, development, agribusiness, partnership and Agribusiness Development Center}

\section{PENDAHULUAN}

Pengembangan UKM terutama UKM, pada era Otonomi Daerah, di sub sektor agribisnis diarahkan melalui konsep pengembangan UKM dengan pendekatan Pengembangan Agribisnis dengan berorientasi pada Kemitraan Strategis Agribisnis, dengan pelibatan berbagai pihak baik pelaku usaha maupun pihak-pihak stakeholders. Oleh karena sebagian besar permasalahan pelaku UKM secara umum maupun UKM agribisnis dikarenakan rendahnya akses pelaku UKM terhadap informasi dan teknologi, manajemen, dan sumber permodalan, sehingga berpengaruh terhadap kualitas produk agribisnis yang dihasilkan. Hal tersebut akan mudah dicapai dengan pendekatan Kemitraan Strategis Agribisnis yang difasilitasi oleh lembaga intermediasi yang diharapkan dapat menjembatani kepentingan pelaku UKM agribisnis dengan pihak-pihak lain baik pemerintah, pelaku UKM lain, swasta, perbankan dan lembaga non perbankan, lembaga penyedia teknologi, dan lembaga-lembaga pendukung lain. Lembaga intermediasi inilah yang nantinya akan berperan aktif dalam mengimplementasikan strategi pengembangan agribisnis dalam upaya membangun kemitraan agribisnis yang akan dilaksanakan oleh pelaku-pelaku UKM agribisnis dan stakeholders terkait. Lembaga intermediasi inilah yang harus diwujudkan terutama oleh Perguruan Tinggi yang berorientasi pada pengembangan agribisnis. Lembaga intermediasi bagi UKM agribisnis ini yang nantinya akan berwujud Pusat Pengembangan Agribisnis (Agribusiness Development Center) inilah yang nantinya akan melakukan berbagai upaya untuk mengembangkan usaha bagi sentra UKM agribisnis yang menjadi binaannya. Berbagai upaya yang akan dilaksanakan oleh Agribusiness Development Center, antara lain layanan informasi, layanan konsultasi, layanan pelatihan, penelitian, fasilitasi dalam perluasan pasar, fasilitasi dalam memperoleh permodalan, fasilitasi dalam pengembangan organisasi dan manajemen, fasilitasi dalam pengembangan teknologi, dan penyusunan rencana pengembangan bisnis. Berbagai upaya tersebut ke depan diharapkan akan dapat meningkatkan kinerja usaha, perbaikan teknis produksi, kelembagaan, manajemen usaha, akses permodalan, dan pemasaran, bagi sentra UKM agribisnis.

Kabupaten Sukoharjo merupakan salah satu daerah sentra agribisnis peternakan sapi di Propinsi Jawa Tengah. Data dari Dinas Pertanian 
Subdin Peternakan Kabupaten Sukoharjo tahun 2008 menunjukkan Populasi ternak sapi di Kabupaten Sukoharjo, dapat dilihat pada Tabel 1 sebagai

Tabel 1. Populasi Ternak Sapi di Kabupaten Sukoharjo Tahun 2008

\begin{tabular}{clc}
\hline No & \multicolumn{1}{c}{ Kecamatan } & Populasi (ekor) \\
\hline 1 & Weru & 4.082 \\
2 & Bulu & 3.625 \\
3 & Tawangsari & 993 \\
4 & Sukoharjo & 492 \\
5 & Nguter & 1.792 \\
6 & Bendosari & 3.192 \\
7 & Polokarto & 4.817 \\
8 & Mojolaban & 5.647 \\
9 & Grogol & 447 \\
10 & Baki & 431 \\
11 & Gatak & 125 \\
12 & Kartasura & 473 \\
\hline & Jumlah & $\mathbf{2 6 . 1 1 6}$ \\
\hline Sumber & Dinas Pertanian Subdin Peternakan Kabupaten Sukoharjo (2008)
\end{tabular}

\section{METODE PENELITIAN}

Metode dasar yang digunakan dalam penelitikan ini adalah metode deskriptif analitis, yakni penelitian yang didasarkan pada pemecahan masalah yang aktual yang ada pada masa sekarang dimana data yang ada mulamula disusun, dijelaskan kemudian dianalisis (metode analitik), dengan menggunakan teknik survey yakni penelitian dengan mengambil sampel dari suatu populasi dengan menggunakan kuesioner sebagai alat pengumpul data yang kemudian ditabulasikan sebagai langkah awal untuk melakukan analisis data (Singarimbun, 1995).

\section{Metode Pengumpulan Data}

Metode Penentuan Lokasi Penelitian

Metode penentuan daerah penelitian dilakukan secara sengaja (purposive) yaitu cara pengambilan daerah penelitian dengan mempertimbangkan alasan yang diteliti dari daerah penelitian
(Singarimbun, 1995). Penentuan lokasi penelitian menggunakan metode Pusposive Sampling atau penentuan daerah yang didasarkan pada karakteristik atau pertimbangan tertentu yang relevan dengan permasalahan penelitian, dimana sebagai lokasi penelitian dipilih Kecamatan Tawangsari, Kabupaten Sukoharjo dengan pertimbangan berdasarkan data pada Tabel 1 menunjukkan bahwa Kecamatan Tawangsari cukup banyak usaha peternakan sapi yang potensial untuk tumbuh dan berkembang, selain dengan kondisi budidaya ternak di daerah tersebut juga sudah cukup baik.

a. Metode Penentuan Responden

Jumlah responden yang diambil sebanyak 60 responden, dengan rincian jumlah peternak sapi sebagai sampel, ditentukan secara proporsional sampling, dengan kriteria responden merupakan pelaku usaha UMKM dengan definisi/batasan pemahaman UMKM yang mengacu pada 
Undang-Undang RI No 20 Tahun 2008 tentang kriteria UMKM, yaitu:

1). Usaha Mikro, memiliki kekayaan bersih paling banyak Rp. 50.000.000,- tidak termasuk tanah dan bangunan tempat usaha, atau memiliki hasil penjualan tahunan paling banyak Rp 300.000.000,-.

2) Usaha Kecil, memiliki kekayaan bersih lebih dari $\mathrm{Rp}$ 50.000 .000 ,- sampai dengan paling banyak Rp 500.000.000,tidak termasuk tanah dan bangunan tempat usaha, atau memiliki hasil penjualan tahunan lebih dari $\mathrm{Rp}$ 300.000 .000 ,- sampai dengan paling banyak $\mathrm{Rp}$ 2.500.000.000,--

3) Usaha Menengah, memiliki kekayaan bersih lebih dari $\mathrm{Rp}$ 500.000.000,- sampai dengan paling Rp10.000.000.000,- tidak termasuk tanah dan bangunan tempat usaha, atau memiliki hasil penjualan tahunan lebih dari $\mathrm{Rp} 2.500 .000 .000$,- sampai dengan paling banyak $\mathrm{Rp}$ 50.000 .000 .000 ,-.(Anonim, 2008).
Penentuan responden dan key informant menggunakan metode Random Sampling atau pengambilan responden secara acak, sehingga setiap individu dalam populasi mempunyai kesempatan yang sama untuk terpilih. Responden penelitian adalah seluruh stakeholders (pemangku kepentingan) baik pemerintah daerah, BAPPEDA, dinas terkait, masyarakat, pelaku usaha, Usaha Besar (BUMD/BUMN), koperasi, konsumen, investor, supplier/lembaga penyedia input dan industri pengolahan, lembaga pembiayaan, serta lembaga pemasaran.

\section{HASIL DAN PEMBAHASAN \\ Umur Peternak}

Usia produktif dan usia tidak produktif dapat mempengaruhi kegiatan yang dilakukan petenak. Berdasarkan hasil penelitian yang dilakukan, diperoleh data jumlah peternak responden berdasarkan umur. Berdasarkan Tabel 2 diketahui bahwa jumlah peternak responden yaitu 60 orang yang terdiri dari 59 orang umur produktif dan 1 orang umur tidak produktif. Hal tersebut menunjukkan bahwa usia responden peternak sebagian besar pada usia produktif (15-64 tahun),

Tabel 2. Jumlah dan Persentase Peternak Berdasarkan Kelompok Umur di Kecamatan Tawangsari

\begin{tabular}{cccc}
\hline \hline No & Kelompok Umur (tahun) & Jumlah Peternak (orang) & $\%$ \\
\hline 1. & $25-30$ & 5 & 8,3 \\
2. & $31-35$ & 3 & 5 \\
3. & $36-40$ & 5 & 5 \\
4. & $41-45$ & 15 & 25 \\
5. & $46-50$ & 12 & 20 \\
6. & $51-55$ & 10 & 16,7 \\
7. & $56-60$ & 7 & 11,7 \\
8. & $61-64$ & 2 & 3,3 \\
9. & $65-70$ & 1 & 1,7 \\
\hline & Jumlah & 60 & 100 \\
\hline \hline
\end{tabular}

Sumber : Analisis data Primer 
yang berarti bahwa dengan usia produktif sebagian besar peternak lebih mudah dalam menerima inovasi/teknologi baru, selain itu juga dengan usia yang masih produktif diharapkan peternak mempunyai motivasi yang besar untuk mengembangkan usaha peternakan mereka, selain itu secara fisik, usia produktif mempunyai kemampuan fisik yang cukup memadai dalam mengelola usaha peternakan sapi.

Sebagian besar usia peternak responden dalam kelompok usia yang produktif. Dimana usia ini berpengaruh terhadap produktivitas kerja peternak. Dengan banyaknya peternak dalam kelompok umur produktif di suatu daerah memungkinkan daerah tersebut dapat berkembang. Hal ini disebabkan peternak lebih mudah menerima informasi, inovasi baru dan lebih cepat mengambil keputusan dalam penerapan teknologi baru yang berhubungan dengan usahataninya. Dengan kondisi tersebut juga diharapkan petani mampu membaca pasar dan memanfaatkan peluang untuk meningkatkan penerimaan usahanya.

\section{Jumlah Anggota Keluarga Peternak}

Jumlah anggota keluarga akan mempengaruhi peternak dalam pengembangan usahanya. Semakin banyak jumlah anggota keluarga menuntut peternak untuk mendapatkan uang yang lebih cepat guna memenuhi kebutuhannya. Selain itu juga semakin banyak jumlah anggota keluarga juga berpengaruh terhadap ketersediaan tenaga kerja. Berikut ini merupakan jumlah anggota kelurga dari peternak responden.

Tabel 3. Jumlah dan Persentase Peternak Berdasarkan Jumlah Anggota Keluarga di Kecamatan Tawangsari

\begin{tabular}{cccc}
\hline \hline No & Anggota Keluarga (orang) & Jumlah (orang) & $\%$ \\
\hline 1. & $1-2$ & 13 & 21,7 \\
2. & $3-4$ & 32 & 53,3 \\
3. & $5-6$ & 10 & 16,7 \\
4. & $7-8$ & 5 & 8,3 \\
\hline \multicolumn{2}{c}{ Jumlah } & 60 & 100 \\
\hline \hline
\end{tabular}

Sumber: Analisis data Primer

Berdasarkan Tabel 3 diketahui bahwa jumlah anggota keluarga dari peternak responden berkisar 3-4 orang sebanyak 32 peternak (53,3\%). Dengan demikian peternak membutuhkan uang tunai untuk bisa mencukupi kebutuhan mereka sehari-hari, sehingga ketika peternak akan memenuhi kebutuhan keluarganya, mereka segera menjual susunya guna mendapatkan uang tunai secepatnya. Tabel 3 juga menunjukkan bahwa ketersediaan tenaga kerja cukup memadai yaitu sekitar 3-4 orang per usaha ternak, sehingga dapat mengurangi biaya tenaga kerja dari luar keluarga.

\section{Jumlah Ternak Yang Dimiliki Peternak}

Kepemilikan ternak oleh peternak akan berpengaruh pada produksi yang dihasilkan. Banyaknya jumlah ternak merupakan salah satu faktor produksi yang penting. Jika produksi yang dihasilkan banyak maka akan berpengaruh juga pada penerimaan dan pendapatan peternak. Berikut ini merupakan jumlah ternak sapi perah dari peternak responden. 
Sugiharti Mulya H, R. Kunto Adi, , Setyowati, Susi Wuri Ani: Strategi...

Tabel 4. Jumlah dan Persentase Peternak Berdasarkan Kepemilikan Ternak di Kecamatan Tawangsari

\begin{tabular}{cccc}
\hline \hline No & Jumlah Ternak (ekor) & Jumlah Peternak (orang) & $\%$ \\
\hline 1. & $1-2$ & 55 & 91,7 \\
2. & $3-5$ & 5 & 8,3 \\
3. & $5-10$ & 0 & 0 \\
\hline \multicolumn{2}{r}{ Jumlah } & 60 & 100 \\
\hline \hline
\end{tabular}

Sumber: Analisis Data Primer

Berdasarkan Tabel 4 diketahui bahwa sebagian besar peternak responden atau 55 peternak $(91,7 \%)$ memiliki ternak berkisar 1-2 ekor, sedangkan peternak yang memiliki ternak 3-5 ekor sebanyak 5 peternak atau $8,3 \%$. Jumlah ternak yang diusahakan peternak sapi relatif sedikit, sehingga produksi yang dihasilkan juga tidak besar. Mereka lebih cenderung untuk langsung menjual sapinya jika memang sudah layak jual, supaya segera mendapatkan uang guna memenuhi jumlah ternak sapi yang dimiliki, maka dapat disimpulkan bahwa sebagian besar peternak sapi di Kecamatan Tawangsari termasuk dalam kategori usaha kecil.

\section{Kelembagaan Peternak}

Kelembagaan peternak juga berpengaruh pada keberhasilan peternak dalam mengelola usahanya, misalnya dalam hal distribusi bibit dan pakan ternak, distribusi atau pemasaran ternak sapi ke pasar atau konsumen, akses permodalan, dan lain-lain.

kebutuhan sehari-hari. Berdasarkan

Tabel 5. Jumlah Peternak Berdasarkan Kelembagaan Peternak (kelompok ternak) di Kecamatan Tawangsari

\begin{tabular}{clcc}
\hline \hline No & Kelompok Ternak & Jumlah Peternak (orang) & $\%$ \\
\hline 1. & KTT Bina Mandiri & 8 & 13,3 \\
2. & Rukun Mulyo I & 5 & 8,3 \\
3. & Rukun Mulyo II & 3 & 5 \\
4. & Rukun Mulyo III & 1 & 1,7 \\
5. & Tidak punya kelompok & 43 & 71,7 \\
\hline \multicolumn{2}{r}{ Jumlah } & 60 & 100 \\
\hline
\end{tabular}

Sumber: Analisis Data Primer

Berdasarkan Tabel 5 diketahui bahwa sebagian besar peternak sapi tidak mempunyai kelompok atau tidak aktif dalam kelompok peternak, hanya $28,3 \%$ peternak saja yang aktif dalam kelompok. Hal tersebut menunjukkan bahwa sebagian besar peternak belum memahami dengan baik peran kelompok peternak untuk mengembangkan usaha mereka, yang dikarenakan mereka menganggap bahwa peran kelompok belum banyak dirasakan manfaatnya oleh sebagian besar peternak, sehingga mereka memutuskan untuk tidak aktif dalam kelompok.

\section{Bentuk Perusahaan}

Bentuk perusahaan pada usaha peternakan sapi akan sangat berpengaruh pada aspek legalitas usaha. Bentuk perusahaan biasanya dipengaruhi oleh besar kecilnya skala usaha. Berikut ini adalah bentuk perusahaan usaha peternakan sapi. 
Tabel 6. Jumlah Dan Persentase Peternak Berdasarkan Bentuk Perusahaan di Kecamatan Tawangsari

\begin{tabular}{clcc}
\hline \hline No & Bentuk Perusahaan & Jumlah Peternak (orang) & $\%$ \\
\hline 1. & Perorangan & 60 & 100 \\
2. & UD & 0 & 0 \\
3. & CV & 0 & 0 \\
4. & Firma & 0 & 0 \\
5. PT & 0 & 0 \\
6. & Lain-lain & 0 & 0 \\
\hline \multicolumn{4}{c}{ Jumlah } \\
Sumber: Analisis Data Primer & 60 & 100 \\
\hline
\end{tabular}

Berdasarkan Tabel 6 diketahui bahwa semua peternak responden atau 60 peternak $(100 \%)$ mempunyai perusahaan dengan bentuk perusahaan perorangan. Hal tersebut menunjukkan bahwa dengan skala usaha yang relatif kecil, mereka menganggap tidak perlu membuat bentuk perusahaan seperti firma, CV, UD, PT dan lain-lain.

Hasil penelitian juga menunjukkan bahwa semua peternak responden tidak ada yang mempunyai ijin usaha, baik SIUP, TDP, HO, SITU, dan lain-lain. Hal tersebut dikarenakan usaha mereka bersifat perorangan, sehingga tidak perlu mengurus ijin usaha dan mereka juga mengkhawatirkan jika ada ijin usaha, maka mereka harus membayar pajak usaha, padahal kapasitas produksi mereka tidak besar.

\section{Volume Penjualan}

Besarnya volume penjualan akan berpengaruh pada besarnya penerimaan yang diterima oleh peternak sapi, baik dari produk utama maupun produk sampingan. Berikut ini adalah besarnya volume penjualan yang dihasilkan oleh peternak sapi.

Berdasarkan Tabel 7 diketahui bahwa sebagian besar peternak responden atau 25 peternak $(41,7 \%)$ volume penjualan untuk produk ternak sapi berkisar Rp 500.000 sd Rp $1.000 .000,-$. Sedangkan untuk produk sampingan volume penjualan untuk kotoran sapi hanya ada 2 orang $(3,3 \%)$

Tabel 7. Jumlah Dan Persentase Peternak Berdasarkan Volume Usaha per bulan di Kecamatan Tawangsari

\begin{tabular}{clcc}
\hline \hline No & \multicolumn{1}{c}{ Jenis Produk } & Jumlah Peternak (orang) & $\%$ \\
\hline 1. Utama : Ternak sapi & 22 & \\
a. Rp 0-500 ribu & 25 & 36,7 \\
b. Rp 500 ribu- 1 juta & 8 & 41,7 \\
c. Rp 1 juta - 1,5 juta & 1 & 13,3 \\
d. Rp 1,5 juta - 2 juta & 4 & 1,7 \\
e. > Rp 2 juta & & 6,7 \\
2. Sampingan : & 2 & \\
a. Kotoran Sapi & 2 & 3,3 \\
1. Rp 0-500 ribu & 0 & 3,3 \\
2. Rp 500 ribu- 1 juta & & 0 \\
\hline b. Urine Sapi & &
\end{tabular}


baik untuk volume penjualan $<\mathrm{Rp}$ 500.000 dan antara Rp $500.000 \mathrm{sd} \mathrm{Rp}$ $1.000 .000,-$. Hal tersebut menunjukkan bahwa produk utama yaitu ternak sapi masih mendominasi volume penjualan produk dan masih menjadi produk andalan dari sebagian besar peternak sapi.

Hasil penelitian juga menunjukkan bahwa untuk produk ternak sapi, peternak sapi tidak dilaksankan dengan sistem pemesanan oleh konsumen atau pedagang. Biasanya pedagang sapi (blantik) yang langsung datang ke peternak, memilih ternak dan langsung dibawa ke pasar hewan. Sedangkan untuk rata-rata tiap pembelian tidak mesti selalu sama, tergantung dari ketersediaan ternak sapi yang dimiliki dan sudah layak jual.

\section{Teknologi Produksi}

Teknologi produksi yang semakin baik akan berpengaruh pada berkembangnya usaha peternakan sapi. Berikut ini adalah teknologi produksi yang dilaksanakan peternak sapi

Tabel 8. Jumlah dan Persentase Peternak Berdasarkan Teknologi Produksi di Kecamatan Tawangsari

\begin{tabular}{lccccc}
\hline \hline No & $\begin{array}{c}\text { Jenis } \\
\text { Teknologi }\end{array}$ & \multicolumn{4}{c}{ Jumlah Peternak (org) } \\
\cline { 3 - 6 } & $\begin{array}{c}\text { Pengolahan } \\
\text { Pakan }\end{array}$ & $\begin{array}{c}\text { Pemberia } \\
\text { n Pakan }\end{array}$ & $\begin{array}{c}\text { Kesehata } \\
\text { n ternak }\end{array}$ & $\begin{array}{c}\text { Reproduksi } \\
\text { ternak }\end{array}$ \\
\hline 1. & Tradisional & 40 & 38 & 0 & 0 \\
2. & Tepat Guna & 20 & 22 & 45 & 0 \\
3. & Modern & 0 & 0 & 15 & 60 \\
\hline & Jumlah & 60 & 60 & 60 & 60 \\
\hline
\end{tabular}

Sumber: Analisis Data Primer

Berdasarkan Tabel 8 diketahui bahwa sebagian besar peternak responden atau 40 peternak $(66,7 \%)$ melaksanakan teknologi pengolahan pakan secara tradisional, sedangkan untuk pemberian pakan sebagian besar juga menggunakan teknologi tradisional, sedangkan untuk kesehatan ternak sebagian besar sudah menggunakan teknologi tepat guna, dan untuk reproduksi ternak semua peternak sudah menggunakan teknologi modern. Hal tersebut menunjukkan bahwa sebagian besar peternak sudah menerapkan teknologi tepat guna dan teknologi modern terutama dalam penanganan kesehatan ternak dan reproduksi ternak. Sedangkan untuk pengolahan pakan dan pemberian pakan, sebagian besar peternak masih menggunakan teknologi tradisional.

\section{Pemasaran Produk}

Pemasaran produk akan berpengaruh pada cepat tidaknya produk bisa sampai kepada konsumen dan wilayah pemasaran produk Berikut ini adalah pemasaran produk ternak sapi.

Berdasarkan Tabel 9 diketahui bahwa sebagian besar peternak responden atau 49 peternak $(81,7 \%)$ memasarkan ternak sapinya untuk pasar lokal atau wilayah Kabupaten Sukoharjo, sedangkan untuk wilayah regional yaitu wilayah Kabupaten Klaten dan Kabupaten Wonogiri, sedangkan untuk wilayah nasional yaitu Kabupaten Purwodadi, Propinsi Jawa Tengah dan Propinsi Banten. 
Tabel 9. Jumlah dan Persentase Peternak Berdasarkan Pemasaran Produk di Kecamatan Tawangsari

\begin{tabular}{clcc}
\hline \hline No & Wilayah Pemasaran & Jumlah Peternak (orang) & $\%$ \\
\hline 1. & Lokal & 49 & 81,7 \\
2. & Regional & 3 & 5 \\
3. & Nasional & 8 & 13,3 \\
\hline \multicolumn{2}{c}{ Jumlah } & 60 & 100 \\
\hline \multicolumn{2}{c}{ Sumber: Analisis Data Primer }
\end{tabular}

\section{Bibit Ternak}

Para peternak memperoleh bibit sapi dari penjual bibit sapi yang sudah menjadi langganan. Oleh karena peternak tahu dan lebih percaya kepada penjual bibit dari sisi higienis dan kualitas bibit sapi yang mereka beli. Penjual bibit sapi ada yang berasal dari desa di sekitar Kecamatan Tawangsari, tetapi ada juga yang luar Kecamatan Tawangsari, bahkan dari luar Kabupaten Sukoharjo, terutama dari Klaten, Jogjakarta. Sistem pembayaran dilakukan secara tunai.

\section{Rantai Nilai Usaha Peternakan Sapi}

Rantai nilai usaha peternakan sapi dimulai dari kegiatan pada sub sistem agribisnis hulu, yaitu pada penyediaan bibit sapi dan sapi bakalan, serta penyediaan sarana produksi (pakan ternak, obat-obatan), sub sistem on farm atau proses produksi mulai dari pemberian pakan sampai dengan menghasilkan sapi siap jual, sub sistem hilir yang meliputi pengolahan hasil dan pemasaran hasil ternak, serta sub sistem pendukung yang meliputi kelembagaan pendukung, pasar, kebijakan pemerintah, dan lain-lain. Secara rinci, rantai nilai usaha peternakan sapi di Kabupaten Sukoharjo pada gambar 1 .

\section{KESIMPULAN}

Hasil pemetaan UKM menunjukkan bahwa usia peternak sebagian besar pada usia produktif, jumlah anggota keluarga peternak berkisar 3-4 orang, sebagian besar peternak adalah tamat SLTP, sebagian besar peternak memiliki ternak berkisar 1-2 ekor, semua peternak menghasilkan ternak sapi dengan kapasitas produksi rata-rata 1,2 ekor/bulan, produk sampingan yaitu kotoran sapi dengan kapasitas produksi rata-rata 100 $\mathrm{kg} /$ bulan, sebagian besar peternak sapi tidak mempunyai kelompok atau tidak aktif dalam kelompok peternak, semua peternak mempunyai perusahaan dengan bentuk perusahaan perorangan, semua peternak pekerjaan utama sebagai peternak sapi, sebagian besar peternak volume penjualan untuk produk ternak sapi berkisar Rp 500.000 sd Rp $1.000 .000,-$, semua peternak menerima pembayaran atas produk yang dijual dengan sistem pembayaran tunai, sebagian besar peternak melaksanakan teknologi tradisional dan modern, sebagian besar peternak memasarkan ternak sapinya untuk pasar lokal dan regional. sebagian besar peternak menjual sapinya kepada pedagang sapi (blantik), sedangkan sisanya menjual langsung di pasar hewan, di daerah Klaten dan Sukoharjo. Persaingan antar peternak tidak banyak terjadi. Hasil analisis SWOT menunjukkan faktor internal, yaitu kekuatan meliputi jumlah 


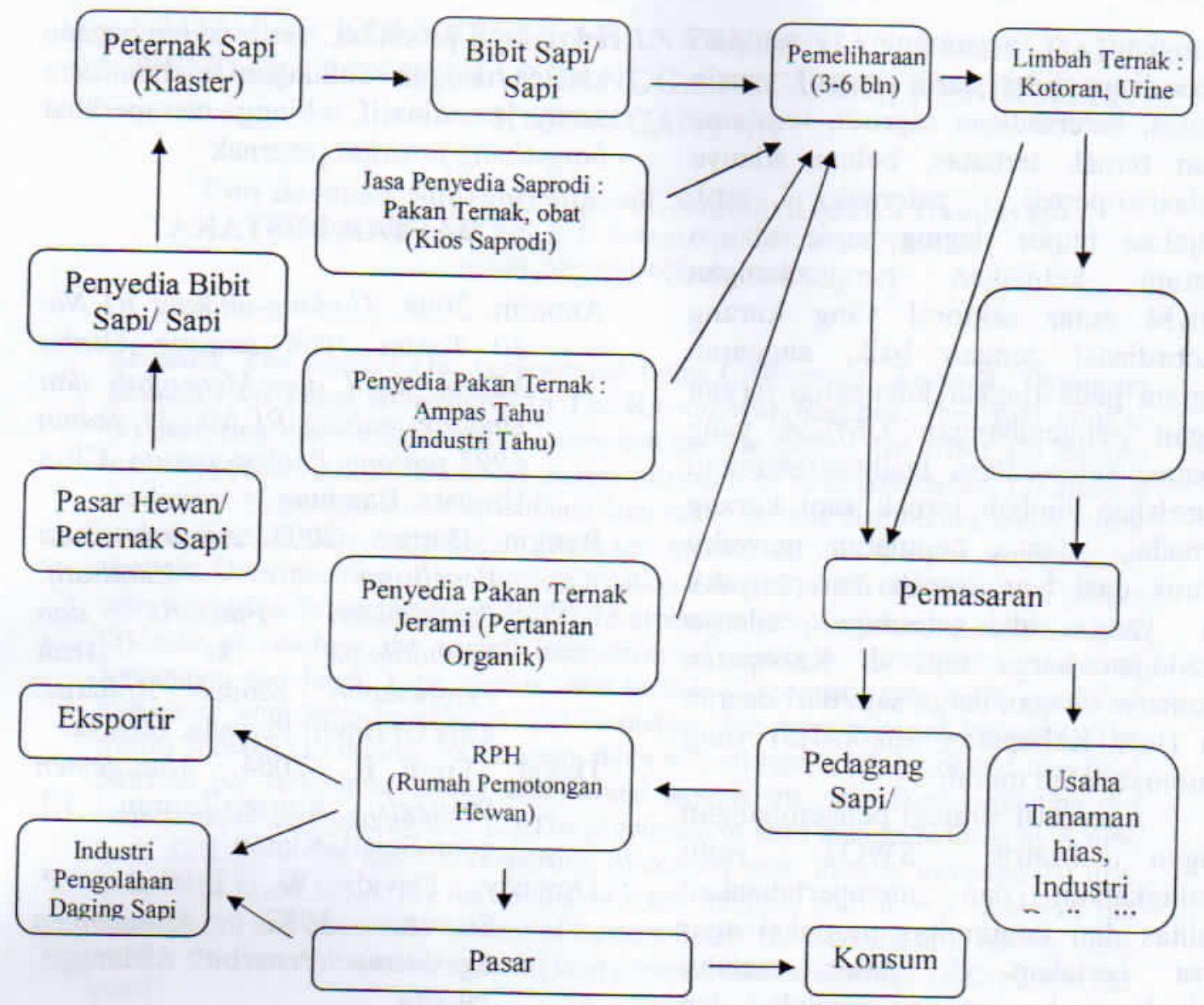

Gambar 1. Rantai Nilai Usaha Peternakan Sapi

kelompok peternak sapi yang cukup besar dan tersebar di Kabupaten Sukoharjo, kualitas sapi yang dihasilkan cukup baik dan produksi sapi yang dihasilkan selama ini selalu terjamin kontinuitas produksinya, potensi SDA yang besar di Kabupaten Sukoharjo, adanya kelembagaan klaster peternakan sapi yang kuat. Sedangkan kelemahan meliputi ketersediaan sarana produksi, terutama pakan ternak berupa jerami dan rumput, serta pakan ternak alternatif kurang memadai, rendahnya kemampuan SDM peternak sapi terhadap akses terhadap teknologi budidaya ternak sapi dan kesehatan hewan, keterbatasan akses terhadap pasar dan informasi harga pasar, pemasaran sapi masih terbatas, pengelolaan ternak sapi selama ini kurang optimal, pengelolaan usaha peternakan sapi selama ini masih dikelola secara tradisional dan turun temurun, keterbatasan modal yang dimiliki peternak. Faktor eksternal yaitu peluang yang meliputi kemudahan akses permodalan pihak perbankan, adanya Lembaga Keuangan Mikro (LKM), juga adanya pinjaman bunga ringan melalui dinas terkait, dan ketersediaan pakan tersebut cukup besar (jerami, rumput, ampas tahu, air limbah tahu), yang disediakan oleh sentra UKM lain, permintaan daging sapi dan produk olahan daging sapi dalam negeri dan ekspor, adanya kebijakan UKM ternak sapi dari anggaran propinsi dan pusat, ketersediaan teknologi atau fasilitas pengolahan limbah ternak sapi, dan kemudahan dalam peningkatan kualitas daging sapi dan peranakan sapi. 
Sedangkan ancaman meliputi ketersediaan bibit sapi unggul masih terbatas, ketersediaan saprodi, terutama pakan ternak terbatas, belum adanya asosiasi/koperasi peternak sapi, kebijakan impor daging sapi, adanya program kebijakan pengembangan UMKM antar sektoral yang kurang terkoordinasi dengan baik, anggaran program pada tingkat kabupaten terkait dengan pengembangan UMKM yang terbatas, ketersediaan fasilitas/teknologi pengolahan limbah ternak sapi kurang memadai, adanya penularan penyakit anthrax dari luar daerah dan penyakit lain yang tidak terduga, adanya persaingan harga sapi di Kabupaten Sukoharjo dengan harga sapi dari daerah lain (luar Kabupaten Sukoharjo) yang umumnya lebih murah.

Alternatif strategi pengembangan
dengan Matrik SWOT yaitu meningkatkan dan mempertahankan kualitas dan kontinuitas produksi agar dapat bertahan di pasar melalui peningkatan kemampuan produksi dan teknologi produksi, serta kelembagaan klaster dengan dukungan stakeholders secara koordinatif, sehingga memperkuat bargaining position peternak, meningkatkan kemampuan SDM peternak dalam rangka meningkatkan akses terhadap saprodi dan teknologi, peningkatan manajemen usaha, mempertahankan dan memperluas akses pasar, melalui koordinasi dan kerjasama dengan stakeholders terkait $\mathrm{di}$ luar pemerintah daerah, dan mempertahankan kualitas, dan kontinuitas produksi melalui kemitraan dengan sentra UKM lain dalam pengadaan saprodi dan jejaring distribusi.

Prioritas strategi pengembangan yang diperoleh dengan Matrik QSP yaitu meningkatkan dan mempertahankan kualitas dan kontinuitas produksi agar dapat bertahan di pasar melalui peningkatan kemampuan produksi dan teknologi produksi, serta kelembagaan klaster dengan dukungan stakeholders secara koordinatif, sehingga memperkuat bargaining position peternak

\section{DAFTAR PUSTAKA}

Anonim. 2008. Undang-undang RI No.

20 Tahun 2008 tentang Usaha Mikro, Kecil dan Menengah dan

Undang-undang RI No. 25 Tahun

1992 tentang Perkoperasian. Citra Umbara. Bandung.

Bungin, Burhan. 2003. Analisis Data

Penelitian

Pemahaman

Metodologis

Filosofis dan

Penguasaan

Raja Grafindo Persada, Jakarta.

David, Fred R. 2004. Manajemen

Strategis; Konsep-konsep. PT intan Sejati. Klaten.

Downey, David, W., Erickson, P. Steven. 1987. Manajemen Agribisnis. Penerbit Airlangga. Jakarta

Firdaus, M. 2008. Manajemen Agribisnis. Bumi Aksara. Jakarta.

Hafsah, J, Mohammad. 2003. Kemitraan Usaha : Konsep dan Strategi. Pustaka Sinar Harapan. Jakarta.

Hunger, J dan Wheelen, T. 2003. Manajemen Strategis. PT Gramedia Pustaka Utama. Jakarta.

Rangkuti, Freddy. 2001. Analisis SWOT Teknik Membedah Kasus Bisnis. Gramedia Pustaka Utama. Jakarta,

Rangkuti, Freddy. 2001. Analisis SWOT Teknik Membedah Kasus Bisnis. Gramedia Pustaka Utama. Jakarta,

Singarimbun, M. 1995. Metode

Penelitian Survei. LP3ES. Jakarta

Umar, H. 2001. Strategic Management in Action. PT Gramedia Pustaka Utama. Jakarta 